\title{
BMJ Open GARFIELD-AF model for prediction of stroke and major bleeding in atrial fibrillation: a Danish nationwide validation study
}

\author{
Frederik Dalgaard (D) , ${ }^{1,2}$ Karen Pieper, ${ }^{2,3}$ Freek Verheugt, ${ }^{4}$ A John Camm, ${ }^{5}$ \\ Keith AA Fox, ${ }^{6}$ Ajay K Kakkar, ${ }^{3,7}$ Jannik L Pallisgaard, ${ }^{8}$ Peter V Rasmussen (D) , ${ }^{1}$ \\ Henk van Weert, ${ }^{9}$ Tommi Bo Lindhardt, ${ }^{1}$ Christian Torp-Pedersen, ${ }^{1,10}$ \\ Gunnar H Gislason, ${ }^{1,11,12}$ Martin H Ruwald (D) , ${ }^{1}$ Ralf E Harskamp ${ }^{9}$
}

To cite: Dalgaard F, Pieper K, Verheugt $\mathrm{F}$, et al. GARFIELD-AF model for prediction of stroke and major bleeding in atrial fibrillation: a Danish nationwide validation study. BMJ Open 2019;9:e033283. doi:10.1136/ bmjopen-2019-033283

- Prepublication history and additional material for this paper are available online. To view these files, please visit the journal online (http://dx.doi. org/10.1136/bmjopen-2019033283).

Received 08 August 2019 Revised 03 October 2019 Accepted 14 October 2019

Check for updates

(C) Author(s) (or their employer(s)) 2019. Re-use permitted under CC BY-NC. No commercial re-use. See rights and permissions. Published by BMJ.

For numbered affiliations see end of article.

Correspondence to Dr Frederik Dalgaard; fdalgaard87@gmail.com

\section{ABSTRACT}

Objectives To externally validate the accuracy of the Global Anticoagulant Registry in the FIELD-Atrial Fibrillation (GARFIELD-AF) model against existing risk scores for stroke and major bleeding risk in patients with nonvalvular AF in a population-based cohort.

Design Retrospective cohort study.

Setting Danish nationwide registries.

Participants 90693 patients with newly diagnosed nonvalvular AF were included between 2010 and 2016, with follow-up censored at 1 year.

Primary and secondary outcome measures External validation was performed using discrimination and calibration plots. C-statistics were compared with $\mathrm{CHA}_{2} \mathrm{DS}_{2}$ VASc score for ischaemic stroke/systemic embolism (SE) and HAS-BLED score for major bleeding/ haemorrhagic stroke outcomes.

Results Of the 90693 included, 51180 patients received oral anticoagulants $(\mathrm{OAC})$. Overall median age $(\mathrm{Q} 1, \mathrm{Q3})$ were $75(66-83)$ years and $48486(53.5 \%)$ were male. At 1-year follow-up, a total of 2094 (2.3\%) strokes/SE, 2642 (2.9\%) major bleedings and 10915 (12.0\%) deaths occurred. The GARFIELD-AF model was well calibrated with the predicted risk for stroke/SE and major bleeding. The discriminatory value of GARFIELD-AF risk model was superior to $\mathrm{CHA}_{2} \mathrm{DS}_{2}$ VASc for predicting stroke in the overall cohort (C-index: $0.71,95 \% \mathrm{Cl}: 0.70$ to 0.72 vs C-index: $0.67,95 \% \mathrm{Cl}: 0.66$ to $0.68, \mathrm{p}<0.001)$ as well as in low-risk patients (C-index: $0.64,95 \% \mathrm{Cl}: 0.59$ to 0.69 vs C-index: $0.57,95 \% \mathrm{Cl}: 0.53$ to $0.61, \mathrm{p}=0.007)$. The GARFIELD-AF model was comparable to HAS-BLED in predicting the risk of major bleeding in patients on OAC therapy (C-index: $0.64,95 \% \mathrm{Cl}: 0.63$ to 0.66 vs $\mathrm{C}$-index: $0.64,95 \%$ Cl: 0.63 to $0.65, p=0.60$ ).

Conclusion In a nationwide Danish cohort with nonvalvular AF, the GARFIELD-AF model adequately predicted the risk of ischaemic stroke/SE and major bleeding. Our external validation confirms that the GARFIELD-AF model was superior to $\mathrm{CHA}_{2} \mathrm{DS}_{2}$ VASc in predicting stroke/SE and comparable with HAS-BLED for predicting major bleeding.

\section{Strengths and limitations of this study}

- This validation study was able to compare prediction performance Global Anticoagulant Registry in the FIELD-Atrial Fibrillation model versus $\mathrm{CHA}_{2} \mathrm{DS}_{2}$ VASc for stroke and HAS-BLED for major bleeding in patients with atrial fibrillation.

- This study used a large contemporary populationbased cohort with atrial fibrillation with many events and very limited loss to follow-up.

- The validation was based on International Classification of Diseases, Tenth Revision coding from the Danish registries which is prone to misclassification bias and lacked clinical measurements.

\section{INTRODUCTION}

Atrial fibrillation (AF) is a common cardiac arrhythmia with a lifetime prevalence of $20 \%-30 \%$ and is the cause of one in four strokes. ${ }^{1} \mathrm{AF}$ is associated with an increased risk of several cardiovascular conditions, most notably a nearly fivefold increased stroke risk. ${ }^{23}$ The risk of stroke can be substantially diminished by thrombotic prophylaxis. ${ }^{45}$ However, $20 \%-40 \%$ of potentially eligible patients do not receiving oral anticoagulant (OAC) therapy. ${ }^{6-8}$ The most important and modifiable contributing factor is inappropriate risk assessment, with underutilisation of existing risk scores, resulting in overestimation of bleeding risks and underestimation of potential stroke risk. ${ }^{9}{ }^{10}$ Recently, the Global Anticoagulant Registry in the FIELDAtrial Fibrillation (GARFIELD-AF) model was developed that allowed for simultaneous calculation of death, stroke and bleeding risks in an international prospective registry of patients with newly diagnosed AF. ${ }^{11}$ In the GARFIELD-AF and ORBIT-AF registries, the GARFIELD-AF model was found to improve 
discrimination of the existing risk scores for stroke $\left(\mathrm{CHA}_{2} \mathrm{DS}_{2}\right.$-VASc) and bleeding (HAS-BLED) ${ }^{11-13}$ These registries may not cover the full spectrum of patients with $\mathrm{AF}$, which warrants external validation of these risk scores in other population-based cohorts. We aimed to (1) externally validate the GARFIELD-AF model of ischaemic stroke and major bleeding outcomes among patients with newly diagnosed AF in a large contemporary Danish cohort and (2) perform a head-to-head comparison of the predictive properties of GARFIELD-AF model with $\mathrm{CHA}_{2} \mathrm{DS}_{2}-\mathrm{VASc}$ for thromboembolic events and HASBLED for major bleeding. We did not externally validate the GARFIELD-AF model for risk of death, as we did not have blood pressure and heart rate measurements; covariates that the GARFIELD-AF model for death requires.

\section{MATERIALS AND METHODS}

We reported our findings according to the transparent reporting of a multivariable prediction model for individual prognosis or diagnosis criteria. ${ }^{14}$

\section{Data sources}

We used the Danish nationwide registers cross-linking The Civil Registration System, The Danish National Patient Register (DNPR) and The Danish Drug Statistical Registry. The Civil Registration System holds data on age, sex and vital status. DNPR contains all hospital admissions according to International Classification of Diseases, Tenth Revision (ICD-10) and procedures. The Danish Drug Statistical Registry was used to characterise pharmacotherapy in which all claimed drug prescriptions are registered. To compare characteristics (baseline and outcomes) of the Danish registry, we used data from the GARFIELD-AF registry which, in brief, is an observational, multicentre, international study of newly diagnosed AF with $\geq 1$ risk factor for stroke. ${ }^{15}$

\section{Study population}

From the DNPR, patients aged $\geq 18$ years with a primary or secondary diagnosis of AF (ICD-10: I48), hospitalisation or outpatient visit were included from 1 January 2010 until 1 August 2016 with follow-up to 1 August 2017. The diagnosis of $\mathrm{AF}$ in the DNPR has a positive predictive value of $94.0 \% .^{16}$ Patients with rheumatic valvular heart disease or valve interventions were excluded. To allow patients time to fill their prescriptions after discharge, a 10-day wash-out period was used. Due to no data on race/ ethnicity in the The Civil Registration System, we excluded immigrants and those with missing information on immigration and presumed Caucasian/European-white for non-immigrants. Given complete nationwide coverage of DNPR, missing data are not present. For baseline characteristic and outcome comparison, we included the worldwide enrolled GARFIELD-AF patients and the patients enrolled from the Scandinavian sites; Denmark, Sweden, Norway and Finland (GARFIELD-AF Scandinavia).
Covariates, GARFIELD-AF model, $\mathrm{CHA}_{2} \mathrm{DS}_{2}$-VASC and HAS-BLED For the Danish AF cohort, all baseline variables were defined from ICD-10 codes, as any primary or secondary diagnosis, inpatient or outpatient, registered up to 10 years prior to the inclusion date. Pharmacotherapy at baseline was identified by Anatomical Therapeutic Chemical codes of prescription drugs claimed up to 180 days prior to the inclusion date. For OAC, within the 180 days, the latest prescription filled of either vitamin $\mathrm{K}$ antagonist (VKA) or non-vitamin K oral anticoagulants (NOAC) was used. Prescriptions claimed for antidiabetic drugs were used as proxy for diabetes mellitus. Hypertension was defined as claimed prescription for a combination of at least two of the seven different antihypertensive drug classes as previously reported. ${ }^{17}$ The algorithm for GARFIELD-AF 1-year risk of ischaemic stroke/systemic embolism (SE) relies on the following variables: age (in years), history of ischaemic stroke, prior bleeding (any recorded in medical records), heart failure (medical history of heart failure or ejection fraction of $<40 \%$ ), chronic kidney disease (CKD) (stages III-V), race/ethnicity and use of OAC (VKA or NOAC). The algorithm for GARFIELD-AF 1-year risk of major bleeding/haemorrhagic stroke was developed in patients taking OAC and involves age, CKD and vascular disease, in which the latter is defined as history of myocardial infarction (MI) or unstable angina, aortic or peripheral artery disease. The $\mathrm{CHA}_{2} \mathrm{DS}_{2}$-VASc score is composed of age, sex, a history of heart failure, hypertension, stroke, transient ischaemic attack, thromboembolism and/or diabetes. HAS-BLED is composed of age, uncontrolled hypertension renal disease, liver disease, labile international normalised ratio (INR), medication use predisposing to bleeding and a history of stroke, major bleeding and/or predisposition to bleeding. All covariates were based on ICD-10 codes. The equations for these respective scores and ICD-10 codes can be found in online supplementary table S1.

\section{Definitions of endpoints}

The primary efficacy endpoint for this study involved a 1-year composite of ischaemic stroke or SE. The primary safety endpoint involved a composite of haemorrhagic stroke or major bleeding. Major bleeding was defined as an organ-specific bleeding requiring hospitalisation. ${ }^{18} \mathrm{~A}$ list of ICD-10 codes used to compute these definitions can be found in Table S2. In the GARFIELD-AF cohorts, the occurrence of 'major bleeding' was defined according to the International Society on Thrombosis and Haemostasis (ISTH) criteria. ${ }^{111519}$

\section{Patient and public involvement}

Patients or the public were not involved in the design of the study.

\section{Statistical analyses}

For the Danish AF cohort, we stratified baseline characteristics by $\mathrm{CHA}_{2} \mathrm{DS}_{2}$-VASc score ( $\leq 2$ for women, $0-1$ for men and $>2$ for women and $>1$ for men). The Danish AF 
cohorts were followed for a maximum of 1-year from the discharge date and until the event of interest (stroke/SE or major bleeding), death, emigration or end of follow-up (August 2017). For all three cohorts (Danish AF cohort, GARFIELD Scandinavia and GARFIELD Global), 1-year absolute risks of stroke/SE and major bleeding were estimated non-parametrically using the Aalen-Johansen estimator with competing risk of death. For the Danish AF cohort, using a logistic regression model, we used the original coefficients from the GARFIELD-AF model development study. The discriminative performance of GARFIELD-AF for predicting ischaemic stroke/SE and major bleeding hospitalisations was assessed using receiver operating characteristics curves and reported as area under the curve (AUC) values. The C-index with 95\% CI was reported as a measure of discrimination. As there was no censoring issue because the data did not contain any loss to follow-up within the first year of the study period, the significance test of C-index differences was tested for significance with DeLongs method..$^{20}$ Calibration was assessed by calculating deciles of predicted probabilities and plotting the average predicting with the observed Kaplan-Meier rate and 95\% CI within each decile. A subgroup analysis for stroke prediction was undertaken for low risk patients. As a sensitivity analysis, we estimated the logistic regression coefficients for each individual covariate used in the GARFIELD-AF models. Statistical analyses were performed using $\mathrm{R}$ software (Team RC. R: A Language and Environment for Statistical Computing, 2019).

\section{RESULTS}

From the Danish registries, a total of 110276 patients were diagnosed with AF between 2010 and 2016. Of those patients, 91836 met the inclusion criteria for the study (Figure S1). Of these, 70020 were identified as high risk and 20673 was identified as low risk of stroke/SE. A total of 51180 were on OACs. From the GARFIELD-AF registries, 52080 patients with AF were included globally, and 2396 patients were included from the Scandinavian sites.

\section{Characteristics of study participants}

Baseline characteristics for all three cohorts (Danish AF cohort, GARFIELD Scandinavia and GARFIELD Global) are shown in table 1. Compared with GARFIELD Scandinavia, the Danish AF cohort had a more equal representation of men and women ( $54 \%$ vs $58 \%$ ) and was older (median age 75 vs 73). There were also notable differences in comorbidities, in which diabetes, hypertension and CKD were less prevalent in the Danish AF cohort, whereas a history of bleeding ( $11.6 \%$ vs $1.9 \%$ vs $2.5 \%)$ was much more prevalent compared with the GARFIELD Scandinavia or global cohorts. Despite these differences, the median $\mathrm{CHA}_{2} \mathrm{DS}_{2}$ Vasc scores were comparable among all cohorts but the HAS-BLED median was higher in the Danish AF cohort. For the GARFIELD model, the median GARFIELD scores were higher in the Danish AF cohort than both GARFIELD cohorts. The use of OAC therapy was $56.4 \%$ in the Danish AF cohort, which was lower than the reported percentages in GARFIELD Scandinavia $(68.0 \%)$ and GARFIELD Global $(60.8 \%)$. The use of aspirin, ADP-inhibitors and non-steroidal antiinflammatory drugs was higher in the Danish AF cohort. The characteristics of patients at low risk $\left(\mathrm{CHA}_{2} \mathrm{DS}_{2}\right.$ Vasc of $0-1$ in men and 1-2 in women; $n=20673$ ) and high risk $(\mathrm{n}=70$ 020) for the Danish AF population are displayed in Table S3. The median (IQR) for $\mathrm{CHA}_{2} \mathrm{DS}_{3}$-VASc and HAS-BLED scores in the high-risk group was $4^{3-5}$ and $2 .^{23}$

\section{Clinical outcomes at 1-year follow-up}

Table 2 displays the number of stroke/SE, major bleeding and all-cause mortality for the Danish AF cohort and GARFIELD-AF cohort. For the Danish AF cohort, over a 1-year follow-up period, a total of 2094 (2.3\%) stroke/ SE, $2642(2.9 \%)$ major bleedings were reported. Annual mortality rates were high with 10915 deaths $(12.0$ per 100 person years). For the OAC-treated patients, there were 4521 deaths (8.8 per 100 person years) and for low risk patients, there were 623 deaths (3.0 per 100 person years). For the GARFIELD-AF Global, the rates of events were lower for stroke/SE (1.2\%), major bleeding (1.1\%) and deaths $(4.7 \%)$. For the GARFIELD-AF Scandinavia, the rates of events were $1.0 \%$ for stroke/SE, $1.7 \%$ for major bleeding $(1.7 \%)$, and $3.7 \%$ for deaths. The cumulative incidence for ischaemic stroke to 1 year for low-risk and high-risk patients are presented in Figure S2 for the Danish AF cohort. The cumulative incidence of stroke/SE and ischaemic stroke for the Danish AF cohort, GARFIELD Scandinavia and GARFIELD Global can be found in figure 1.

\section{External validation of GARFIELD-AF model}

The C-index for the GARFIELD-AF model for 1-year stroke was 0.71 (95\% CI: 0.70 to 0.72 ) in the overall Danish $\mathrm{AF}$ cohort of 90693 patients and 0.64 (95\% CI: 0.59 to 0.69 ) in low-risk patients not requiring OAC therapy $(\mathrm{n}=20673)$. The C-index for the GARFIELD-AF model for 1-year major bleeding risk was 0.64 (95\% CI 0.63 to 0.66$)$ in patients using OAC therapy. The GARFIELD-AF model for stroke/SE and major bleeding scores were both well calibrated in the Danish AF cohort (figures 2 and 3). The individual covariates in the GARFIELD-AF model expressed a similar regression coefficient for most covariates in the Danish cohort when compared with the original derivation GARFIELD-AF cohort (online supplementary table S4).

\section{GARFIELD-AF model versus $\mathrm{CHA}_{2} \mathrm{DS}_{2}$-VASc score for predicting stroke/SE}

The AUC curves for predicting stroke using the GARFIELD model and $\mathrm{CHA}_{2} \mathrm{DS}_{2}$-VASc scores are displayed in figure $4 \mathrm{~A}$ for the Danish $\mathrm{AF}$ cohort and figure $4 \mathrm{~B}$ for the low risk patients. The AUC and corresponding C-index for GARFIELD was significantly higher when compared with $\mathrm{CHA}_{2} \mathrm{DS}_{2}$ Vasc for predicting stroke outcomes, in the overall cohort (C-index: $0.71,95 \%$ CI: 0.70 to 0.72 vs $0.67,95 \%$ CI: 0.66 to 0.68 ) as well as in 
Table 1 Baseline characteristics of patients from the Danish AF cohort, GARFIELD-AF Scandinavia and GARFIELD-AF Global registries

\begin{tabular}{|c|c|c|c|}
\hline & Danish AF cohort & GARFIELD-AF Scandinavia & GARFIELD-AF Global \\
\hline$n$ & 90693 & 2396 & 52080 \\
\hline Age (median (IQR)) & $75(66.0,83.0)$ & $73.0(66.0,78.0)$ & $71.0(63.0,78.0)$ \\
\hline Sex, male (\%) & $48486(53.5)$ & $1389(58.0)$ & $29068(55.8)$ \\
\hline Race, Caucasian (\%) & NA & $1860(99.3)$ & $32028(63.1)$ \\
\hline Diabetes (\%) & $10900(12.0)$ & $387(16.2)$ & 11555 (22.2) \\
\hline Stroke/TIA (\%) & $12827(14.1)$ & $325(13.6)$ & $3879(7.5)$ \\
\hline SE (\%) & $448(0.5)$ & $6(0.3)$ & $335(0.6)$ \\
\hline History of bleeding (\%) & $10544(11.6)$ & $46(1.9)$ & $1318(2.5)$ \\
\hline Vascular disease (\%) & $15305(16.9)$ & $268(11.2)$ & $7682(14.8)$ \\
\hline Chronic kidney disease (\%) & $4224(4.7)$ & $185(7.7)$ & $5360(10.3)$ \\
\hline Heart failure (\%) & $14961(16.5)$ & $348(14.5)$ & $11758(22.6)$ \\
\hline Ischaemic heart disease (\%) & $13445(14.8)$ & $331(13.8)$ & $11265(21.6)$ \\
\hline Hypertension (\%) & $55665(61.4)$ & $1659(69.4)$ & $39643(76.3)$ \\
\hline VTE or PE (\%) & $5141(5.7)$ & $77(3.2)$ & $1355(2.6)$ \\
\hline NOAC (\%) & $23212(25.6)$ & $521(21.7)$ & $11004(21.1)$ \\
\hline VKA (\%) & $27968(30.8)$ & $1110(46.3)$ & 20708 (39.8) \\
\hline OAC (\%) & $51180(56.4)$ & $1631(68.0)$ & $31712(60.8)$ \\
\hline $\mathrm{VKA}+\mathrm{AP}(\%)$ & $10773(11.9)$ & $181(7.6)$ & $4827(9.4)$ \\
\hline $\mathrm{NOAC}+\mathrm{AP}(\%)$ & $7608(8.4)$ & $47(2.0)$ & $1896(3.7)$ \\
\hline NSAID (\%) & $13078(14.4)$ & $23(1.0)$ & $1701(3.3)$ \\
\hline Acetylsalicylic acid (\%) & $32890(36.3)$ & $413(17.2)$ & $14636(28.1)$ \\
\hline ADP-inhibitor (\%) & $9128(10.1)$ & $89(3.7)$ & $3580(6.9)$ \\
\hline CABG (\%) & 3291 (3.6) & $92(3.9)$ & 1625 (3.2) \\
\hline $\mathrm{CHA}_{2} \mathrm{DS}_{2} \mathrm{VASC}$ (median (IQR)) & $3.0(2.0,4.0)$ & $3.0(2.0,4.0)$ & $3.0(2.0,4.0)$ \\
\hline \multicolumn{4}{|l|}{$\mathrm{CHA}_{2} \mathrm{DS}_{2}$ VASC $(\%)$} \\
\hline 0 & $5678(6.3)$ & $19(0.8)$ & $1516(2.9)$ \\
\hline 1 & $10231(11.3)$ & $279(11.7)$ & $6369(12.4)$ \\
\hline 2 & $16137(17.8)$ & $530(22.2)$ & $10230(19.9)$ \\
\hline 3 & $20143(22.2)$ & $626(26.2)$ & $12138(23.6)$ \\
\hline 4 & $19378(21.4)$ & $526(22.1)$ & $11022(21.4)$ \\
\hline 5 & $11020(12.2)$ & $238(10.0)$ & 5895 (11.5) \\
\hline$>5$ & $8106(8.9)$ & $167(7.0)$ & $4238(8.2)$ \\
\hline HAS-BLED (median (IQR)) & $2.0(1.0,3.0)$ & $1.0(1.0,2.0)$ & $1.0(1.0,2.0)$ \\
\hline HAS-BLED category $n$, missing (\%) & & $1088(1308)$ & 37549 (14 531-missing) \\
\hline 0 & $8297(9.1)$ & $169(15.5)$ & $5471(14.6)$ \\
\hline 1 & $19956(22.0)$ & $507(46.6)$ & $16169(43.1)$ \\
\hline 2 & $31170(34.4)$ & $301(27.7)$ & $11692(31.1)$ \\
\hline 3 & $24998(27.6)$ & $87(8.0)$ & $3570(9.5)$ \\
\hline$>3$ & $6272(6.9)$ & $24(2.2)$ & $647(1.7)$ \\
\hline GARFIELD-AF model, stroke, median (IQR) & $1.10(0.75,1.82)$ & $0.80(0.60,1.10)$ & $0.90(0.70,1.40)$ \\
\hline GARFIELD-AF model, bleed, median (IQR) & $1.08(0.74,1.54)$ & $0.90(0.70,1.30)$ & $1.00(0.70,1.40)$ \\
\hline
\end{tabular}

AP, antiplatelet therapy; CABG, coronary artery bypass grafting; GARFIELD-AF, Global Anticoagulant Registry in the FIELD-Atrial Fibrillation; NA, Not available; NOAC, non-vitamin-K antagonist; NSAID, non-steroidal anti-inflammatory drug; OAC, oral anticoagulants; PE, pulmonary embolism; SE, systemic embolism; TIA, transient ischaemic attack; VKA, vitamin-K antagonist; VTE, venous thromboembolism. 
Table 2 Number of events and deaths for 1-year follow-up in the Danish population (all patients, patients on OAC, low-risk patients), GARFIELD-AF Global and GARFIELD-AF Scandinavia

\begin{tabular}{|c|c|c|c|c|c|}
\hline & $\begin{array}{l}\text { Danish AF } \\
\text { cohort }(n=90 \\
693)\end{array}$ & $\begin{array}{l}\text { Patients } \\
\text { treated with } \\
\text { OAC }(n=51 \\
180)\end{array}$ & $\begin{array}{l}\text { Low-risk } \\
\text { patients } \\
(n=20673)\end{array}$ & $\begin{array}{l}\text { GARFIELD } \\
\text { Scandinavia } \\
(\mathrm{n}=2396)\end{array}$ & $\begin{array}{l}\text { GARFIELD-AF Global } \\
(\mathrm{n}=52080)\end{array}$ \\
\hline Ischaemic Stroke/SE & 2094 & 994 & 139 & 24 & 599 \\
\hline $\begin{array}{l}\text { Major bleeding/haemorrhagic } \\
\text { stroke }\end{array}$ & 2642 & 1492 & 242 & $28^{*}$ & $341 \dagger$ \\
\hline
\end{tabular}

Low-risk patients were defined as $\mathrm{CHA}_{2} \mathrm{DS}_{2}$-VASc score ( $\leq 2$ for women, $0-1$ for men and $>2$ for women and $>1$ for men).

${ }^{*}$ Of those treated with OAC $(\mathrm{n}=1631)$

†Of those treated with OAC $(n=31712)$

AF, atrial fibrillation; GARFIELD-AF, Global Anticoagulant Registry in the FIELD-Atrial Fibrillation; OAC, oral anticoagulation; SE, systemic embolism.

low-risk patients (C-index: $0.62,95 \%$ CI: 0.59 to 0.69 vs $0.57,95 \%$ CI: 0.53 to 0.61$)$.

\section{GARFIELD-AF model versus HAS-BLED score for predicting major bleeding/haemorrhagic stroke}

Figure 4C illustrates the AUC curves for the prediction of major bleeding based on the GARFIELD and HAS-BLED scores in patients taking OAC therapy. The discriminatory value of GARFIELD was comparable with HAS-BLED: C-index: 0.64 (95\% CI: 0.63 to 0.66$)$ versus C-index: 0.64 (95\% CI: 0.63 to 0.65 ), respectively.

Table 3 displays available evidence comparing the discriminatory properties of various models for stroke/ SE and major bleeding.

\section{DISCUSSION}

In a large unselected contemporary Danish AF cohort, our study demonstrates that the GARFIELD-AF model

A Stroke/SE

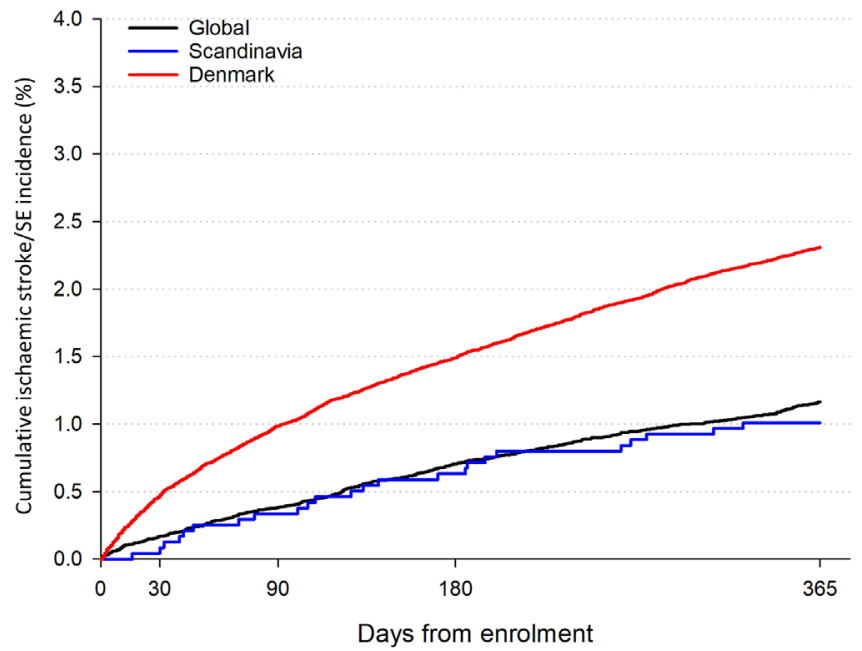

serves as a reliable risk stratification tool. We found that the GARFIELD-AF model surpasses the widely used $\mathrm{CHA}_{2} \mathrm{DS}_{2}$-VASc score in predicting the risk of stroke, both in high-risk and low-risk patients. For predicting major bleeding, the three-item GARFIELD-AF model is on par with HAS-BLED among anticoagulated patients with AF.

Risk-stratification of patients with AF is essential to mitigate the risk of stroke/SE when initiating anticoagulation therapy. As such, the easy-to-calculate $\mathrm{CHA}_{2} \mathrm{DS}_{2}$-VASc score serves as the risk-stratification tool recommended by international guidelines to commence therapy when the risk of stroke reaches a threshold of $>2 \%$ per annum. ${ }^{21}$ Prior studies have shown that guideline-adherent (riskstratified) anticoagulation therapy is associated with a $60 \%-70 \%$ reduction in thromboembolic associated complications and mortality. ${ }^{22}$ Despite these reductions in stroke risk, there is still room for improvement in risk stratification of patients with $\mathrm{AF}$ and anticoagulation

B

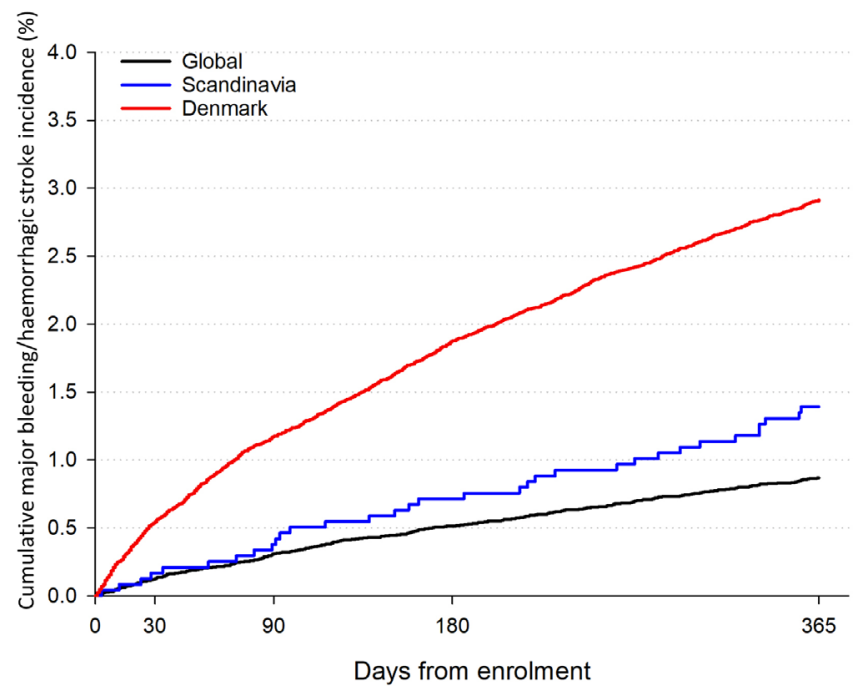

Figure 1 Cumulative incidence of stroke/SE (panel A) and major bleeding (panel B) in the Danish AF cohort, GARFIELD-AF Scandinavia and GARFIELD-AF Global. AF, atrial fibrillation; GARFIELD-AF, Global Anticoagulant Registry in the FIELD-Atrial Fibrillation; SE, systemic embolism. 
A

Calibration 1-Year Stroke Risk - (Low Risk)

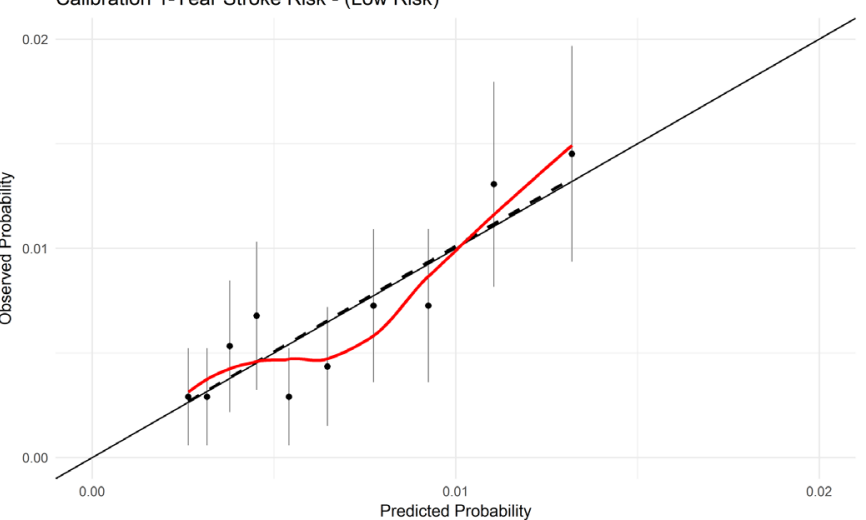

B

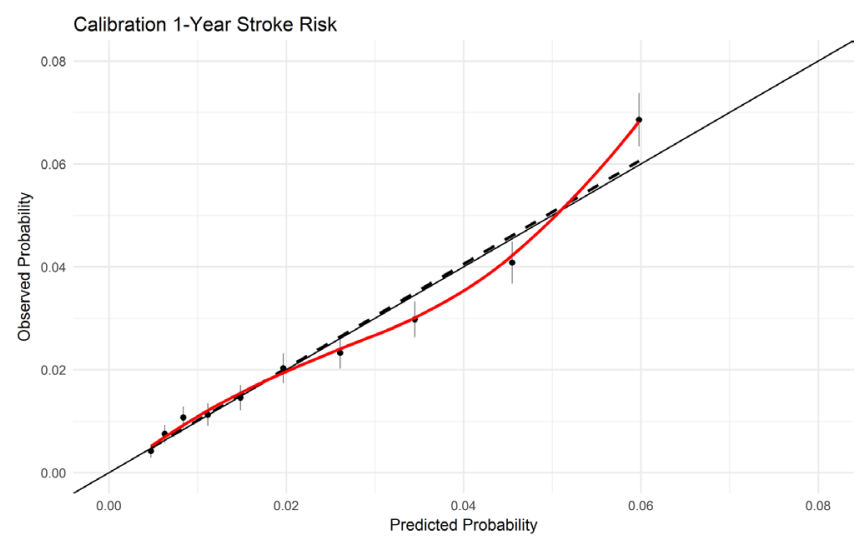

Figure 2 Calibration plots of GARFIELD-AF model and stroke/SE risk in overall Danish population (A) and in low-risk patients (B). Predicted probability for GARFIELD (blackline), and actual observed cumulative incidence estimates with $95 \% \mathrm{Cl}$ for each GARFIELD score in deciles including a linear regression model (dashed line) and LOESS function of observed probability (red line). GARFIELD-AF, Global Anticoagulant Registry in the FIELD-Atrial Fibrillation; SE, systemic embolism.

therapy. In this regard, the GARFIELD-AF model, which calculates the risk of stroke, death and major bleeding, is promising, particularly as it performed better than the $\mathrm{CHA}_{2} \mathrm{DS}_{2}$ VASc and HAS-BLED. ${ }^{11}$ The GARFIELD-AF model is not a risk score that is categorised into risk groups but instead it provides risk prediction on a continuous scale. As the model provides risk estimates of stroke/ SE and bleeding (and mortality when blood pressure and heart rate data are available) in one single calculation based on routinely collected data, it could have potentially wide clinical applications.

Underuse of anticoagulation therapy is a well-known problem in particular in high-risk patients. ${ }^{23}$ Our study found that $73.1 \%$ of patients with increased stroke risk $\left(\mathrm{n}=51180, \mathrm{CHA}_{2} \mathrm{DS}_{2-} \mathrm{VASc}>2\right.$ in women and $>1$ in men) received anticoagulation therapy. Studies suggest that treatment barriers are based on overestimation of

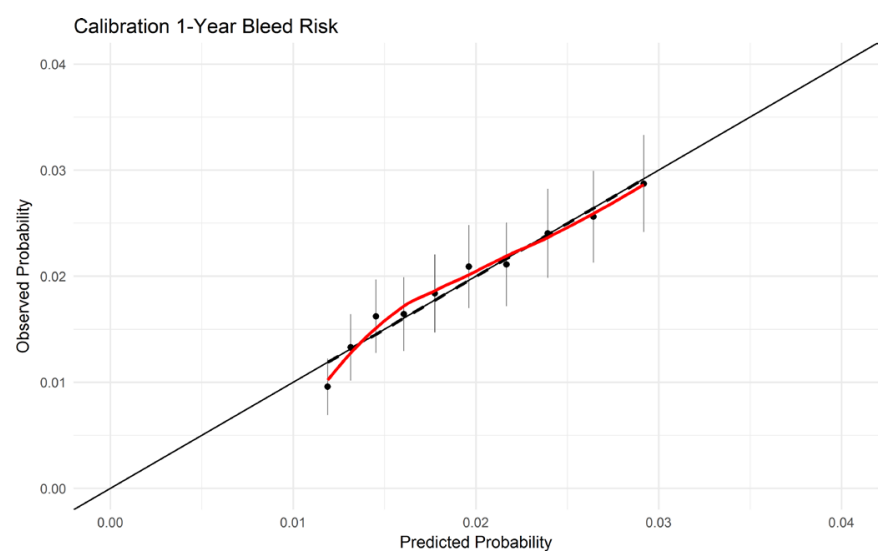

Figure 3 Calibration plots of GARFIELD-AF model and major bleeding risk in Danish population. Predicted probability for GARFIELD (blackline), and actual observed cumulative incidence estimates with $95 \% \mathrm{Cl}$ for each GARFIELD score in deciles including a linear regression model (dashed line) and LOESS function of observed probability (red line). GARFIELD-AF, Global Anticoagulant Registry in the FIELD-Atrial Fibrillation. bleeding risks (eg, recurrent falls and prior peptic ulcers) and lack of reliable risk stratification tools and readily available information that does not rely on specific laboratory tests such as HAS-BLED. ${ }^{9} 1023$

To provide predictions for bleeding risk, several bleeding scores have been developed, of which HASBLED has been most rigorously tested. ${ }^{24}{ }^{25}$ While the HAS-BLED risk score is clinically useful to identify patients at high bleeding risk, it requires information that may not always be available in outpatient and primary care settings, such as information on liver function tests, INR status and the presence of anaemia. This may be a limitation for the implementation of this score in low-resource settings and is of relevance as the majority $(60 \%)$ of community-dwelling patients with $\mathrm{AF}$ are seen in primary care. ${ }^{26}{ }^{27}$ Moreover, primary care physicians achieve lower anticoagulation rates compared with hospital-based physicians. ${ }^{28}{ }^{29}$ While there are multiple reasons for these differences, which include differences in populations, with high percentage of (relative) contraindications $(40 \%-65 \%)$ and care-related factors, the lack of an integral decision tool impedes informed decisions on initiating or continuing antithrombotic therapy. ${ }^{10} 30$

In the present study, the external validation show that GARFIELD-AF is well calibrated with the predicted risks, and the good calibration aligns well with the original GARFIELD-AF derivation cohort. ${ }^{11}$ GARFIELD-AF score has improved discriminatory abilities compared with $\mathrm{CHA}_{2} \mathrm{DS}_{2}$-VASc score in stroke prediction and on par with HAS-BLED for bleeding prediction. To our surprise, our external validation of GARFIELD-AF discriminatory c-index for stroke prediction was slightly higher $(0.71)$ than the c-index in the original GARFIELD cohort (0.69). Furthermore, the Danish AF cohorts were older with more stroke events than both GARFIELD cohorts and higher predicted risk than the GARFIELD cohorts. The opposite was the case for major bleeding prediction where the original GARFIELD cohort had better 

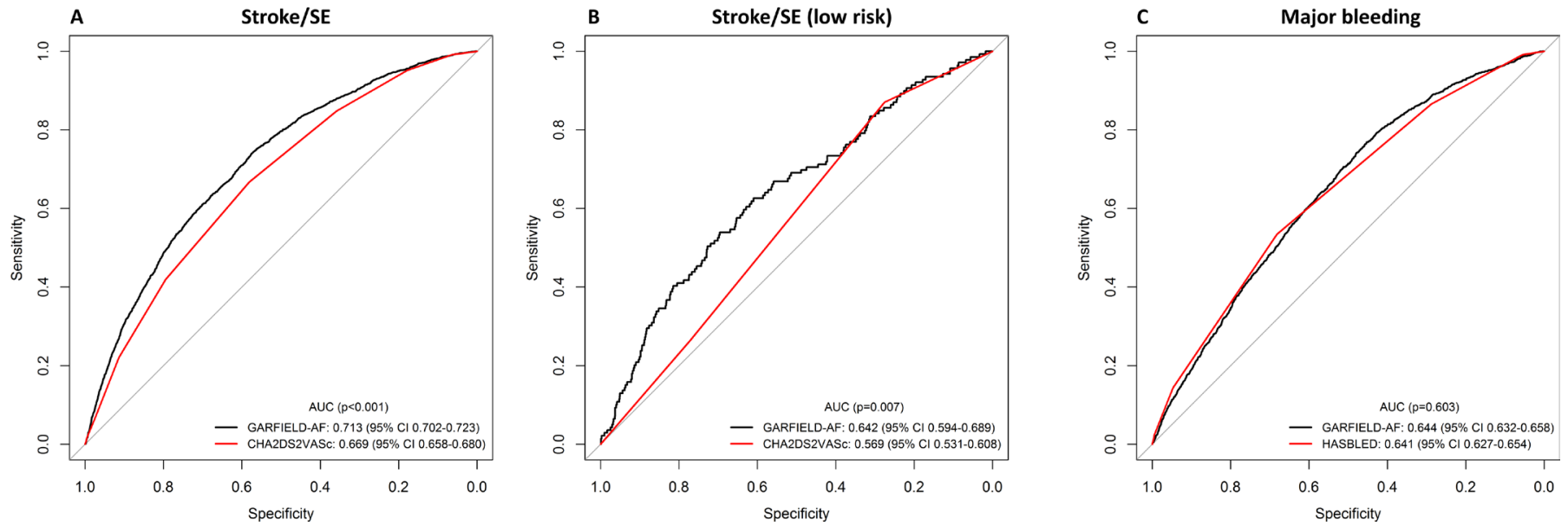

Figure 4 Receiver Operating Characteristic curves of GARFIELD-AF model versus $\mathrm{CHA}_{2} \mathrm{DS}_{2} \mathrm{VASc}$ scores for predicting stroke in (A) the Danish AF cohort and (B) low-risk individuals, and (C) GARFIELD-AF model versus HAS-BLED scores for predicting major bleeding in the Danish AF cohort in those receiving oral anticoagulants $(n=51180)$. Low-risk stroke patients were defined as $\mathrm{CHA}_{2} \mathrm{DS}_{2}$-VASc score ( $\leq 2$ for women, $0-1$ for men and $>2$ for women and $>1$ for men). AF, atrial fibrillation; GARFIELD-AF, Global Anticoagulant Registry in the FIELD-Atrial Fibrillation.

discriminatory abilities than HAS-BLED. The significant differences in the cohort characteristics, for example, higher HAS-BLED and more use of combined OACs and antiplatelet therapy in the Danish AF cohort, and definitions of covariates and outcomes are likely to play a key role in both instances.

The value of $\mathrm{CHA}_{2} \mathrm{DS}_{2}$-VASc score in defining patients with a truly low risk of stroke is uncertain, partly because the number of patients to accurately assess lower risk patients in the original studies was insufficient. ${ }^{12} 31$ The evaluation of the performance of risk scores in this lowrisk category is important, as it determines the threshold when initiating antithrombotic therapy outweighs the risk of bleeding. In our study although both models had modest predictive discrimination for low-risk patients, we found that in these patients, the GARFIELD-AF model was well calibrated and provided a better prediction than $\mathrm{CHA}_{2} \mathrm{DS}_{2}$-VASc score in indicating which patients are truly at low risk for subsequent stroke.

\section{Limitations and future directions}

The primary limitation of this study is that definitions are based on administrative ICD-10 codes which are prone to non-systematic misclassification bias. Discrepancies exist between the GARFIELD-AF registry and the Danish registries in the definitions of comorbidities and clinical outcome data. This was most notable for major bleeding and stroke/SE events and CKD. In the Danish AF cohort, selected ICD-10 codes for bleeding hospitalisations were applied, whereas GARFIELD-AF applied the ISTH criteria for major bleeding, which are more restrictive. Apart from differences in disease definitions, the

Table 3 Available evidence comparing the discriminatory properties of various models for stroke/SE and major bleeding ${ }^{1124}$

\begin{tabular}{|c|c|c|c|c|}
\hline Outcome & Cohort & $\mathbf{N}$ & $\begin{array}{l}\text { GARFIELD-AF-AUC (95\% } \\
\text { Cl) }\end{array}$ & $\begin{array}{l}\mathrm{CHA}_{2} \mathrm{DS}_{2}-\mathrm{VASc} \\
\text { /HAS-BLED-AUC (95\% } \\
\text { Cl) }\end{array}$ \\
\hline \multirow{2}{*}{ Stroke/SE } & ORBIT-AF & 9743 & 0.69 (0.64 to 0.75$)$ & $0.69(0.64$ to 0.74$)$ \\
\hline & Danish AF cohort & 90693 & 0.71 (0.70 to 0.72 ) & 0.67 (0.66 to 0.68$)$ \\
\hline \multirow[t]{4}{*}{ Major bleeding } & GARFIELD-AF & 25677 & 0.66 (0.62 to 0.69$)$ & 0.64 (0.61 to 0.68$)$ \\
\hline & ORBIT-AF & 7442 & 0.61 (0.58 to 0.64$)$ & - \\
\hline & SPORTIF III-V & 3550 & 0.56 (0.54 to 0.57$)$ & $0.58(0.56$ to 0.60$)$ \\
\hline & Danish AF cohort & 51180 & 0.64 (0.63 to 0.66$)$ & $0.64(0.63$ to 0.65$)$ \\
\hline
\end{tabular}

AUC, area under the curve; GARFIELD-AF, Global Anticoagulant Registry in the FIELD-Atrial Fibrillation; ORBIT-AF, The Outcomes Registry for Better Informed Treatment of Atrial Fibrillation; SE, systemic embolism; SPORTIF, The Stroke Prevention Using Oral Thrombin Inhibitor in Atrial Fibrillation. 
relative high number of bleeding and stroke/SE events in the Danish AF cohort could also be explained by site of enrolment (only hospital/out-patient). Similar data limitations apply to the construction of $\mathrm{CHA}_{2} \mathrm{DS}_{2}$-VASc score and HAS-BLED scores which was calculated from ICD-10 code usage although this study followed the standards set by other researchers using the same Danish registries. ${ }^{17}$ Specifically, we were unable to account for labile INR component of the HAS-BLED score. Another limitation was the inability to ascertain ethnicity status which is an integrated covariate of the GARFIELD-AF model. Therefore, we excluded immigrants to strengthen the assumption of European/Caucasian ethnicity in the cohort. The GARFIELD Scandinavian cohort consisted of 99.3\% Caucasians. Population-based studies in other more ethnically diverse cohorts are warranted. We did not asses net reclassification improvement as this statistic is not appropriate when using it for point-based scores, such as $\mathrm{CHA}_{2} \mathrm{DS}_{2}-\mathrm{VASc}^{32}$ For the implementation of the GARFIELD-AF model, an online risk calculator already exists. A next step would be to provide an electronic health record integrated solution, in which stroke/SE and bleeding risks are automatically calculated when a patient is identified with AF. Doing so would promote balanced and evidence-based decision-making on anticoagulation therapy. Integrating the GARFIELD-AF model into electronic health records would also provide a way for anonymous monitoring of outcomes of patients in which the GARFIELD-AF model was applied, which can be used to further optimise risk prediction.

\section{CONCLUSION}

The GARFIELD-AF model adequately predicted the risk of ischaemic stroke/SE and major bleeding/haemorrhagic stroke in a nationwide Danish cohort of contemporary patients with non-valvular $\mathrm{AF}$. Our external validation confirms that the performance of the GARFIELD-AF model was superior to $\mathrm{CHA}_{2} \mathrm{DS}_{2}$ VASc in predicting stroke/ SE both in high-risk and in low-risk patients and comparable with HAS-BLED for predicting major bleeding. The GARFIELD-AF model holds an advantage over the existing risk scores as it permits for simultaneous evaluation of death, stroke and bleeding risks and uses readily available clinical parameters. As such, the tool may lead to more informed treatment decisions, improve monitoring for bleeding complications and improve outcomes for patients treated for AF in the community.

\footnotetext{
Author affiliations

${ }^{1}$ Cardiology, Gentofte Hospital, Hellerup, Copenhagen, Denmark

${ }^{2}$ Duke Clinical Research Institute, Duke University, Durham, United States

${ }^{3}$ Department of Clinical Research, Thrombosis Research Institute, London, UK

${ }^{4}$ Onze Lieve Vrouwe Gasthuis, Amsterdam, Noord-Holland, the Netherlands

${ }^{5}$ Department of Cardiology, University of London St George's Molecular and Clinical Sciences Research Institute, London, UK

${ }^{6}$ Cardiology, University of Edinburgh and Royal Infirmary of Edinburgh, Edinburgh, UK

${ }^{7}$ Department of Surgery, University College London, London, United Kingdom

${ }^{8}$ Department of Cardiology, Bispebjerg Hospital, Kobenhavn, Denmark
}

${ }^{9}$ Department of General Practice, Amsterdam UMC, Amsterdam Public Health and Amsterdam Cardiovascular Sciences Research Institutes, Academic Medical Center, University of Amsterdam, Amsterdam, the Netherlands

${ }^{10}$ Department of Clinical Investigation and Cardiology, Nordsjællands Hospital, Hillerod, Denmark

${ }^{11}$ The Danish Heart Foundation, Copenhagen, Denmark

${ }^{12}$ The National Institute of Public Health, University of Southern Denmark, Odense, Denmark

Twitter Frederik Dalgaard @F_dalgaard

Acknowledgements We would like to thank the investigators and participants involved in the GARFIELD-AF registry, Madhusudana Rao for programming support of GARFIELD-AF tables and Saverio Virdone for statistical support of GARFIELD-AF survival curves.

Contributors FD, RH, MR, FV, KF, AKK, HVW and KP contributed to the study concept and design; FD and KP conducted the data analysis; REH and FD drafted the manuscript; FD, REH, MR, FV, KF, AKK, HVW, JC, JP, PVR, TBL, CTP and GHG critically reviewed all drafts of the manuscript.

Funding REH reports salary support from The Netherlands Organization for Scientific Research (NWO) through a RUBICON-grant to study bleeding risks associated with NOAC use. FD is funded by Danish Heart Foundation (Grant no: 17-R115-A7443-22062) and Gangstedfonden (Grant no. A35136) and reports trave grants from Knud Højgaard Fonden, Torben og Alice Frimodts Fond. KP is funded by the Duke Clinical Research Institute.

Competing interests KF has received research grants Bayer/Janssen and AstraZeneca and Consulting/Fees Bayer, Sanofi/Regeneron and Verseon. FV has received honoraria for consulting and presentations from Bayer HealthCare, Boehringer Ibgelheimy, BMSPfizer and Daiichi-Sankyo. GHG has ownership of stocks in Novo Nordisk Pharmaceuticals and reports research grants from Pfizer, Bristol Myers Squibb, Boehringer Ingelheim and Bayer. CTP declares grants for studies from Bayer. Other authors have no conflicts of interest to declare.

Patient consent for publication Obtained.

Ethics approval For the GARFIELD-AF registry, an independent ethics committee and hospital-based institutional review board approvals were obtained for the registry protocol. In Denmark, retrospective register studies do not require approval from the ethics committees. The Danish Data Protection Agency approved this study (Ref no: 2007-58-0015, I-Suite no: 02732, GEH-2014-014). Data were made available in an anonymised format such that specific individuals could not be identified.

Provenance and peer review Not commissioned; externally peer reviewed.

Data availability statement Due to restrictions related to Danish law and protecting patient privacy, the combined set of data as used in this study can only be made available through a trusted third party, Statistics Denmark. This state organisation holds the data used for this study. Any request on data access should be addressed to Statistics Denmark https://www.dst.dk/en.aspx\#

Open access This is an open access article distributed in accordance with the Creative Commons Attribution Non Commercial (CC BY-NC 4.0) license, which permits others to distribute, remix, adapt, build upon this work non-commercially, and license their derivative works on different terms, provided the original work is properly cited, appropriate credit is given, any changes made indicated, and the use is non-commercial. See: http://creativecommons.org/licenses/by-nc/4.0/.

\section{ORCID iDs}

Frederik Dalgaard http://orcid.org/0000-0002-7287-4191

Peter V Rasmussen http://orcid.org/0000-0002-4593-3854

Martin H Ruwald http://orcid.org/0000-0002-1541-309X

\section{REFERENCES}

1 Lloyd-Jones DM, Wang TJ, Leip EP, et al. Lifetime risk for development of atrial fibrillation: the Framingham heart study. Circulation 2004;110:1042-6.

2 Odutayo A, Wong CX, Hsiao AJ, et al. Atrial fibrillation and risks of cardiovascular disease, renal disease, and death: systematic review and meta-analysis. BMJ 2016;354.

3 Wolf PA, Abbott RD, Kannel WB. Atrial fibrillation as an independent risk factor for stroke: the Framingham study. Stroke 1991;22:983-8. 
4 Hart RG, Pearce LA, Aguilar MI. Meta-Analysis: antithrombotic therapy to prevent stroke in patients who have nonvalvular atrial fibrillation. Ann Intern Med 2007;146:857-67.

5 Ruff CT, Giugliano RP, Braunwald E, et al. Comparison of the efficacy and safety of new oral anticoagulants with warfarin in patients with atrial fibrillation: a meta-analysis of randomised trials. Lancet 2014;383:955-62.

6 Cowan C, Healicon R, Robson I, et al. The use of anticoagulants in the management of atrial fibrillation among general practices in England. Heart 2013;99:1166-72.

7 Huisman MV, Rothman KJ, Paquette M, et al. Antithrombotic treatment patterns in patients with newly diagnosed nonvalvular atrial fibrillation: the GLORIA-AF registry, phase II. Am J Med 2015;128:1306-13.

8 Wilke T, Groth A, Mueller S, et al. Oral anticoagulation use by patients with atrial fibrillation in Germany. adherence to guidelines, causes of anticoagulation under-use and its clinical outcomes, based on claims-data of 183,448 patients. Thromb Haemost 2012;107:1053-65.

9 Cox JL, Parkash R, Abidi SS, et al. Optimizing primary care management of atrial fibrillation: the rationale and methods of the integrated management program advancing community treatment of atrial fibrillation (IMPACT-AF) study. Am Heart J 2018;201:149-57.

10 van Doorn S, Hartman-Weide F, Geersing G-J, et al. Reasons for non-adherence to practice guidelines on stroke prevention in patients with atrial fibrillation: a cross-sectional study in primary care. Int J Cardiol 2015;187:525-6.

11 Fox KAA, Lucas JE, Pieper KS, et al. Improved risk stratification of patients with atrial fibrillation: an integrated GARFIELD-AF tool for the prediction of mortality, stroke and bleed in patients with and without anticoagulation. BMJ Open 2017;7:e017157.

12 Lip GYH, Nieuwlaat R, Pisters R, et al. Refining clinical risk stratification for predicting stroke and thromboembolism in atrial fibrillation using a novel risk factor-based approach: the Euro heart survey on atrial fibrillation. Chest 2010;137:263-72.

13 Pisters R, Lane DA, Nieuwlaat R, et al. A novel user-friendly score (HAS-BLED) to assess 1-year risk of major bleeding in patients with atrial fibrillation: the Euro heart survey. Chest 2010;138:1093-100.

14 Collins GS, Reitsma JB, Altman DG, et al. Transparent reporting of a multivariable prediction model for individual prognosis or diagnosis (TRIPOD): the TRIPOD statement. BMJ 2015;350:g7594.

15 Kakkar AK, Mueller I, Bassand J-P, et al. International longitudinal registry of patients with atrial fibrillation at risk of stroke: global anticoagulant registry in the field (Garfield). Am Heart $J$ 2012;163:13-19.

16 Schmidt M, Schmidt SAJ, Sandegaard JL, et al. The Danish national patient registry: a review of content, data quality, and research potential. Clin Epidemiol 2015;7:449-90.

17 Olesen JB, Lip GYH, Hansen ML, et al. Validation of risk stratification schemes for predicting stroke and thromboembolism in patients with atrial fibrillation: nationwide cohort study. BMJ 2011;342:d124.

18 van Rein N, Heide-Jørgensen U, Lijfering WM, et al. Major bleeding rates in atrial fibrillation patients on single, dual, or triple antithrombotic therapy. Circulation 2019;139:775-86.
19 Schulman S, Kearon C,Subcommittee on Control of Anticoagulation of the Scientific and Standardization Committee of the International Society on Thrombosis and Haemostasis. Definition of major bleeding in clinical investigations of antihemostatic medicinal products in non-surgical patients. J Thromb Haemost 2005;3:692-4.

20 DeLong ER, DeLong DM, Clarke-Pearson DL. Comparing the areas under two or more correlated receiver operating characteristic curves: a nonparametric approach. Biometrics 1988;44:837-45.

21 Kirchhof P, Benussi S, Kotecha D, et al. 2016 ESC Guidelines for the management of atrial fibrillation developed in collaboration with EACTS. Eur Heart J 2016;37:2893-962.

22 Lip GYH, Laroche C, Popescu MI, et al. Improved outcomes with European Society of cardiology guideline-adherent antithrombotic treatment in high-risk patients with atrial fibrillation: a report from the EORP-AF General pilot registry. Europace 2015;17:1777-86.

23 Ogilvie IM, Newton N, Welner SA, et al. Underuse of oral anticoagulants in atrial fibrillation: a systematic review. Am J Med 2010;123:638-45.

24 Proietti M, Rivera-Caravaca JM, Esteve-Pastor MA, et al. Predicting bleeding events in anticoagulated patients with atrial fibrillation: a comparison between the HAS-BLED and GARFIELD-AF bleeding scores. J Am Heart Assoc 2018;7:e009766.

25 Yao X, Gersh BJ, Sangaralingham LR, et al. Comparison of the $\mathrm{CHA}_{2} \mathrm{DS}_{2}$-VASc, CHADS, ${ }_{2}$ HAS-BLED, ORBIT, and ATRIA Risk Scores in Predicting Non-Vitamin K Antagonist Oral AnticoagulantsAssociated Bleeding in Patients With Atrial Fibrillation. Am J Cardiol 2017;120:1549-56.

26 Das M, Panter L, Wynn GJ, et al. Primary care atrial fibrillation service: outcomes from consultant-led anticoagulation assessment clinics in the primary care setting in the UK. BMJ Open 2015;5:e009267.

27 Kirchhof P, Schmalowsky J, Pittrow D, et al. Management of patients with atrial fibrillation by primary-care physicians in Germany: 1-year results of the atrium registry. Clin Cardiol 2014;37:277-84.

28 Apenteng PN, Gao H, Hobbs FR, et al. Temporal trends in antithrombotic treatment of real-world UK patients with newly diagnosed atrial fibrillation: findings from the GARFIELD-AF registry. BMJ Open 2018;8:e018905.

29 Turakhia MP, Hoang DD, Xu X, et al. Differences and trends in stroke prevention anticoagulation in primary care vs cardiology specialty management of new atrial fibrillation: the retrospective evaluation and assessment of therapies in AF (TREAT-AF) study. Am Heart $J$ 2013;165:93-101.

30 Adderley N, Ryan R, Marshall T. The role of contraindications in prescribing anticoagulants to patients with atrial fibrillation: a crosssectional analysis of primary care data in the UK. Br J Gen Pract 2017;67:e588-97.

31 Friberg L, Skeppholm M, Terént A. Benefit of anticoagulation unlikely in patients with atrial fibrillation and a CHA2DS2-VASc score of $1 . J$ Am Coll Cardiol 2015;65:225-32.

32 Thomas LE, O'Brien EC, Piccini JP, et al. Application of net reclassification index to non-nested and point-based risk prediction models: a review. Eur Heart $J$ 2019;40:1880-7. 